\title{
Bilateral NonpalpableCryptorchidism In Adults; Does Social Class InfluencePresentation?
}

\author{
Samaila I Shu'aibu ${ }^{1}$ Ofoha CGideon ${ }^{1}$ Akpayak ICletus ${ }^{1}$ Venyir M Ramyil ${ }^{1}$ Nuhu \\ K Dakum ${ }^{1}$ \\ Salihu B Makama ${ }^{2}$ Joy A.R Shuaibu ${ }^{3}$ Edwin Oseni-Momodu ${ }^{3}$ \\ ${ }^{1}$ Division of Urology, Department of Surgery, Jos University TeachingHospital, Jos \\ ${ }^{2}$ Department of Surgery, Abubakar Tafawa BalewaUniversity Teaching Hospital, Bauchi \\ ${ }^{3}$ Department of Surgery, Bingham University Teaching Hospital, Jos
}

\begin{abstract}
The study investigated the social class profile of adults with bilateral non-palpablecryptorchidism in NorthernNigeria. Methods: A 5 year retrospective review of adults with bilateral non-palpable testes presenting in 3 tertiary health facilities in Northern Nigeria was done. Social classification was done according to the Registrar General's classification. Patients' presenting complaint, laparoscopy findings and definitive therapy offered were analysed, and presented as tables and percentages. Chi square was used to test for significance in occurrence of cryptorchidism between Social Classes.Results:28 patients' records were available for review. Mean age at presentation was 28.5 years. Social Class II patients constituted $3.6 \%$ of the study population, $32.1 \%$ were in Social Class III, and $39.3 \%$ were in Social Class IV while 25\% were in Social Class $V(p=0.220)$. The main reasons for consultation were primary infertility in $42.8 \%$ and empty scrotum in $50 \%$. One patient $(3.6 \%)$ presented with features of metastatic testicular carcinoma. Diagnostic laparoscopy was done in only $45 \%$ ofpatients. Treatment consisted of an orchidopexy in $75.9 \%$ cases and orchidectomy in 18.5\%.Conclusion: There is a difference in occurrence of cryptorchidism betweensocial classes. This can be partly explainedby deprivation and poor socioeconomic conditions in life. Patients may come to the fore when being evaluated for infertility. It is necessary to increase awareness, health educate the populace and elevate socioeconomic status to avoid late presentation.
\end{abstract}

Key Words: Adults, Cryptorchidism, Social Class.

\section{Introduction}

Cryptorchidism is one of the commonest genital anomalies in boys. By the end of the first year of life cryptorchidism has an incidence of about $1 \%$ and remains so through out life. The prevalence of bilateral cryptorchidism in Nigerian children was found to be $0.3 \%$. [1]

In developed countries, the existence of undescended testicles in adult population is rare, which could be due to systematic practice of elective orchidopexy before the second year of life as well as orchidectomy in post-adolescent patients with undescended testicles [2].In regions of the world where low socioeconomic status and ignorance predominate, adults present with cryptorchidism.[3]The aim of management of cryptorchidism among others is to perform orchidopexy before second year of life in order to avert infertility and ensure early detection assuming malignant transformation supervenes. For a disease with such grave consequences, it is appalling that patients present in adulthood when health care providers can do little to overcome the aforementioned complications. The authors theorisethere is a difference in occurrence of cryptorchidism between social classes. It is also hypothesized that increasing awareness, health education and elevation in socioeconomic status can improve health seeking behavior of patients and perhaps lead to early detection and treatment of diseases such as cryptorchidism.

In this manuscript the authors seek to describe the social and clinical profile of adults presenting with bilateral nonpalpable cryptorchidism in 3 tertiary health centers in Northern Nigeria.

\section{Methods}

This is a 5 year (2008-2012)retrospective, multicenter cohort descriptive study.Available records of 28adults who presented with bilateral nonpalpable cryptorchidism in 3 tertiary healthcenters in Northern Nigeria were retrieved. Data analysed were age, social class, presentingcomplaint, diagnosticlaparoscopic findings anddefinitive surgical procedure done. Social classificationwas done according to the Registrar General's classification [4] whereClass I represents professional occupations, Class II represents managerial and technical occupations, Class III represents skilled non-manual and skilled manual occupations, Class IV represents partly skilled occupations and Class V represents unskilled occupations. Results wereanalyzed using SPSS version 16 
and presentedas means, percentages and tables. Chi square was used to test for significance in occurrence of cryptorchidism between Social Classes.

\section{Results}

28 patients' records were available for analysis. Age range was $22-43$ with amean of 28.5 years. $3.6 \%$ were in Class II, $32.1 \%$ were in social class III, and $39.3 \%$ were in social class IV while $25 \%$ were class $\mathrm{V}(\mathrm{p}=0.220)$.(Table 1$)$.

\begin{tabular}{llll} 
Class & Number & Percentage & \\
\hline I & - & - & \\
II & 1 & 3.6 & \\
& & & \\
III & 9 & 32.1 & \\
IV & 11 & 39.3 & \\
V & 7 & 25 & \\
\hline Total & 28 & 100
\end{tabular}

Table 1 Social class of patients

$42.8 \%$ of patients presented because of infertility or were detected during a work up for infertility. $50 \%$ complained of empty scrotum. One patient $(3.6 \%)$ presented with sudden abdominal pain, another patient (3.6\%) presented with features of metastatic testicular carcinoma with elevatedserum B- HCG. This patient was subsequently lost to follow up before any intervention could be offered (.Table 2)

\begin{tabular}{lll} 
Complaint & Number & Percentage \\
\hline Infertility & & $\mathbf{4 2 . 8}$ \\
Malignancy & $\mathbf{1 2}$ & $\mathbf{3 . 6}$ \\
Sudden abdominal pain & $\mathbf{1}$ & $\mathbf{3 . 6}$ \\
Empty Scrotum & $\mathbf{1}$ & $\mathbf{5 0}$ \\
\hline Total & $\mathbf{1 4}$ & $\mathbf{1 0 0}$
\end{tabular}

Table 2 Presenting Complaint

. Testosterone levels were normal in all patients.All patients who presented on account of infertility and had semen fluid analysis were azoospermic. 13 patients (45\%) had diagnostic laparoscopy (Table 3 )

\begin{tabular}{ll} 
Finding & Number \\
\hline Bilateral intra-abdominal testes & $\mathbf{9}$ \\
Unilateral Intra-abdominal testes & $\mathbf{3}$ \\
Persistent Mullerian Structures & $\mathbf{1}$ \\
\hline Total & $\mathbf{1 3}$
\end{tabular}

Table 3 Findings On laparoscopy in 13 patients

Of the 54 nonpalpable testes evaluated, 34 (63\%) testicles were intrabdominal, 12(22.2\%) were located at the inguinal canal, $5(9.3 \%)$ were at the internal ring or just proximal to it, $3(5.5 \%)$ were vanishing.

One stage orchidopexy was done in 41 testes. Ten orchidectomies were done due to testicular atrophy or failure to achieve a tension free dependent position that will allow subsequent assessment. Biopsies of the undescended testes were not routinely taken with only $38 \%$ of testes having had biopsies.

\section{Discussion}

The main finding of this study is that more than $90 \%$ of the adults with cryptorchidism were ina social class III and IV and V. These are low income earning professions. Conversely none of the patients were in the high income earningSocial Class I. Although this finding was not statistically significant $(\mathrm{p}=0.220)$, the fact that low socioeconomic status influences virtually all spheres of life including health is a recurringdecimal. Once a person assumes a sick role, it is observed that he/she seeks medical advice and cooperates with medical experts while seeking for medical care. Health seekers in Nigeria, like any developing country, tend to do so based on the resources at the disposal of the family. Several other factors are involved in health seeking behaviour among households in Nigeria. These factors include; the severity of the symptoms of illness, socio-cultural influences, distance, place and cost of treatment, income, level of education and quality of health care facilities $[5,6]$.The influence of distance, place and cost of treatment were not analysed in this study. Schellenberg et al, have reported the occurrence of an association between socioeconomic status and health seeking behaviour; with low socioeconomic status people seeking frequently government health care rather than private medical facilities [7]. This is buttressed by the finding in this study that all patients sought care in government facilities, yet again cost 
and availability of expertise mighthave influenced the decision to seek care in government facilities. Another study in Bangledash found that socio-economic status was the single most pervasive determinant of health seeking behavior among the study population overriding age and sex [8]

Whereas this study didn't directly assess the reasons for delay in presenting, a previous study in North-Central Nigeria, (Tanimo et al) found the major reason for delay in seeking treatment as reported by more than half of respondents $(56.9 \%)$ was the thought that they would get over the ailment without treatment. About a quarter $(25.4 \%)$ of respondents delayed because of lack of money for treatment while, distance to the health facility was the reason for $5.1 \%$ of respondents' delay[9]. The aforementioned reasons would have played a part in the delayed presentation of these patients.

Health Insurance Scheme is the most reasonable option for financing health care in this part of the world. The apparent slow pace in the implementation of the scheme will continue to deprive a large number of patients access to timely and good health care. The universal call for education and eradication of poverty is one that should be heeded to improve health care and increase its accessibility.

A significant problem caused by bilateral cryptorchidism is infertility.Two critical prepubertal steps are defective in the cryptorchid patient, and are partly responsible for infertility (i) the transformation of the primitive stem cell pool (gonocytes) into the adult stem cell pool (Ad spermatogonia) at 2-3 months of life and (ii) transformation of Ad spermatogonia into the primary spermatocytes at $4-5$ years of age $[10,11]$.The infertilemale moreoften than not has a deflated sense of self worth and self- fulfillment which is difficult to accurately evaluate clinically. In this study $42.8 \%$ of patients presented on account of infertility.About $10 \%$ of infertile men have a history of cryptorchidism and orchidopexy [12].Bilateral cryptorchid men have a 6-fold greater risk of being infertile when compared with unilaterally cryptorchid men and general population [13]. The incidence of azoospermia in men with unilateral cryptorchidism is $13 \%$ regardless of the fate of the testis. Among men with untreated bilateral cryptorchidism, 98\% develop azoospermia [13].All patients that presented on account of infertility in this study had azoospermia. The changes in spermatogenesis are virtually "cast in stone" by the first year of life, therefore for all patients with adult bilateral cryptorchidism, fertility is almost always not a consideration in their management, early tumourdetection is.

One patient in this study had Persistent Mullerian duct Syndrome (PMDS). This refers to a form of internal male pseudohermaphroditism characterized by the presence of Mullerian duct derivatives (uterus, Fallopian tube, upper part of vagina) in an otherwise normal male. The exact cause of PMDS is not known; however, it is thought to result from the defects of the synthesis or release of Mullerian inhibitory factor (MIF) or from the MIF receptor defect. The MIF gene has been localized to the short arm of Chromosome 19. MIF, released by the Sertoli cells of the fetal testis from seven weeks gestation onwards, is responsible for the regression of the Müllerian duct in the male fetus. A defect of the MIF gene leads to the persistence of the uterus and the fallopian tube in the male. It is likely that these remnant Müllerian structures produce cryptorchidism by hindering the normal testicular descent mechanism [14].

Another patient in the index study had features of metastatic testicular carcinoma.This is not surprising seeing that cancer risk of an ectopic testis is 40 times higher in a normal testis and an abdominal testis is four times more likely to undergo malignant degeneration than an inguinal testis[15]. The cancer of undescended testes usually peaks in the third or fourth decade of life [15].Tumor in an abdominal testis is more likely to be seminoma, but tumors in testes previously corrected by orchidopexy are more likely to be nonseminomas [16].Orchidopexy does not eliminate cancer risk but allows an early diagnosis by making testicles accessible to exploration [17].

Laparoscopy is by far the most sensitive and specific procedure to localise an undescended testis. Its accuracy rates vary from $88-100 \%$ and it's widely used as the first step in management of the non-palpabletestis [18].Sadly only $46 \%$ of the study population had this procedure, mainly due to non availability of equipment or lack of technical expertise.In majority of adult patients, cryptorchid testis is intra-abdominal either at the deep ring or high intra-abdominally. Lojanapiwat et al reported intra-abdominal testis in $95 \%$ of adult patients with cryptorchidism [19]. Large percentage of the testes inthis position further emphasizes the benefit of laparoscopy in obviating unnecessary inguinal exploration and disrupting normal inguinal canal mechanism. Orchidectomies were done in the index study in atrophic testes or when it was impossible to achieve a tension free placement without compromising vascular integrity.

This study is not without limitations. It is a retrospective survey, the nature of which cannot rule out a recall bias of the collected data. The multicentre nature of the study also meant different surgeons had different protocols for managing adult cryptorchid patients.

\section{Conclusion}

There is a difference in presentation of cryptorchidism betweensocial classes. This can be partly explained by deprivation and poor socioeconomic conditions in life. Delay in providing care for cryptorchid 
patients can be costly and dangerous, it is necessary to increase awareness and to health educate people on this problem.

\section{References}

[1] Adeoti ML, Fadiora SO, Oguntola AS, Aderounmu AO, Laosebikan DA, Adejumobi OO. Cryptorchidism in a local population in Nigeria. West Afr J Med 2004;23:62-4

[2] Darzi AA, Aliramaji A, Ramezani MS. Unresolved abdominal mass in an adult cryptorchid testis: a case report. Int J Gen Med 2010;3:395-8

[3] Osifo OD, Evbuomwan I. Undescended testis in a developing country. A study of management of 71 patients. Afr $J$ PeadiatricSurg.2008;5:11-4

[4] Socio-economic indicators. Available at www.celsius.Isthm.ac.uk/modules /Socio/se04000.html. Accessed June 30th 2013.

[5] HERFON, Nigerian Health Review, 2006. Health Reform Foundation of Nigeria. Available at www.herfon.org/resource centre/nhr.htm. Accessed May 282013.

[6] HERFON, Nigerian Health Review, 2007. Primary Health Care in Nigeria: 30 Years After Alma Ata. Available at www.herfon.org/resource centre/nhr.htm. Accessed May 282013.

[7] Schellenberg JA, Victora CG, Mushi A, de Savigny D, Schellenberg D, Mshinda H, Bryce J. Inequities among the very poor: health care for children in rural southern Tanzania. J Bio Soc Sci. 1992; 24:143-55.

[8] Ahmed SM,Toomson G, PetzoldM, Kabir ZN, Socio-economic status overrides age and gender in determining health seeking behavior in rural Bangledash Bulletin of the World Heath Organisation 2005; 83;109-17\}

[9] Tanimola, Akande M, Owoyemi JO.Healthcare-Seeking Behaviour in Anyigba,North-Central, Nigeria Research Journal of Medical Sciences. 2009;3:47-51

[10] Hadziselimovic F. Cryptorchidism, its impact on male infertility. Eur Urol 2002;41:123-3

[11] Hadziselomovic F, Zivkovic D, Bica DTG et al. The Importance of minipuberty for fertility in cryptorchidism. J Urol 2005; 174:1536-9

[12]. Grasso M, Buonaguidi A, Lania C. Postpubertal cryptorchidism: review and evaluation of fertility. Eur Urol. 1991; 20:126-8.

[13]. Lee P. Fertility in cryptorchidism: does treatment make a difference? Endocrinol Metabol Clin North Am. 1993; 22:479-90.

[14] Josso N, Belville C, di Clemente N, Picard JY. AMH and AMH receptor defects in persistent móllerian duct syndrome. Hum ReprodUpdate 2005; 11:351-6.

[15] Alshyarba MH. A giant intra-abdominal testicular seminoma. Biomed Res. 2010; 21(3):227-9.

[16] Chandrasekharan LV, Abdl Ghaffar T, Venkatramana M, Rath S. A case of teratocarcinoma. Internet J Radiol. 2005; 4(1) In: Abdominal testis: a case report. Available http://www.ispub.com/journal/the internet journal of radiology/volume 4 number 1 46/article/a case of teratocarcinoma in abdominal testis a case report.html. Accessed 26 May, 2013.

[17] Cristián Palma C, Cristóbal B, Maccioni R. Seminoma in an adult cryptorchid testis (intra-abdominal): a case report Actas Urol Esp. 2007; 31(2):160-3.

[18] Moor RG, Peters CA, Bauers SB. Laparoscopic evaluation of the nonpalpable testis: a prospective assessment of accuracy. $J$ Urol $1994 ; 151: 728-30$

[19] Lojanapiwat B. Soonthornpun S, Wudhikam S. Preoperative laparoscopy in the management of the non palpable testis. $J$ Med AssocThai 1999; 82:1106-10 